\title{
Intravoxel incoherent motion magnetic resonance imaging for breast cancer: A comparison with benign lesions and evaluation of heterogeneity in different tumor regions with prognostic factors and molecular classification
}

\author{
MING ZHAO ${ }^{1}$, KUANG FU ${ }^{1}$, LEI ZHANG ${ }^{2}$, WENHUI GUO ${ }^{1}$, QIONG WU $^{1}$, \\ $\mathrm{XUE} \mathrm{BAI}^{1}$, ZIYAO $\mathrm{LI}^{2}$, QIANG GUO ${ }^{2}$ and JIAWEI TIAN ${ }^{2}$ \\ Departments of ${ }^{1}$ MRI Diagnosis and ${ }^{2}$ Ultrasound, The Second Affiliated Hospital of Harbin Medical University, \\ Harbin, Heilongjiang 150086, P.R. China
}

Received December 4, 2017; Accepted May 22, 2018

DOI: $10.3892 / \mathrm{ol} .2018 .9312$

\begin{abstract}
The objective of the present study was to compare the differentiation between breast cancer and benign breast lesions and study regional distribution characteristics in various subtypes of breast cancer using intravoxel incoherent motion (IVIM) parameters. This retrospective study involved 119 patients with breast cancer and 22 patients with benign breast lesions, who underwent 3.0T breast magnetic resonance imaging examinations. The apparent diffusion coefficient (ADC) and IVIM parameters (slow ADC, fast ADC and fraction of fast ADC) were obtained from patients with breast cancer and benign lesions using diffusion-weighted imaging (DWI) with b-values of $0,50,100,150,200,400,500,1,000$ and $1,500 \mathrm{sec} / \mathrm{mm}^{2}$. Compared with patients with benign breast lesions, patients with breast cancer exhibited decreased ADC $(\mathrm{P}<0.001)$, slow ADC $(\mathrm{P}<0.001)$ and fast ADC $(\mathrm{P}<0.001)$ values, and higher fraction of fast $\mathrm{ADC}(\mathrm{P}<0.001)$ values. Tumors with metastatic axillary lymph nodes demonstrated increased fraction of fast $\mathrm{ADC}$ values $(\mathrm{P}<0.001)$ and decreased slow ADC values $(\mathrm{P}<0.001)$ compared with tumors without metastatic axillary lymph nodes. The Fast ADC values of tumor tissues in estrogen receptor (ER) and progesterone receptor (PR) negative groups were higher than in positive groups $(\mathrm{P}<0.001)$, and the slow ADC values of tumor tissues were lower in ER and PR negative groups than positive groups $(\mathrm{P}<0.001)$. Luminal $\mathrm{B}$ (HER2- negative) tumor $(\mathrm{P}<0.001)$ and peritumor $(\mathrm{P}<0.001)$ tissues exhibited decreased fraction of fast $\mathrm{ADC}$ values, in
\end{abstract}

Correspondence to: Professor Jiawei Tian, Department of Ultrasound, The Second Affiliated Hospital of Harbin Medical University, 148 Bao Jian Road, Harbin, Heilongjiang 150086, P.R. China

E-mail: xgxdblxd@sina.com

Key words: diffusion-weighted imaging, intravoxel incoherent motion, breast cancer, benign breast lesions comparison with other subtypes. Triple-negative breast cancer (TNBC) tumor tissue exhibited increased fast ADC $(\mathrm{P}<0.001)$ and fraction of fast ADC values $(\mathrm{P}<0.001)$, and decreased slow ADC values $(\mathrm{P}<0.001)$, when compared with other subtypes. The TNBC tumor edge tissues had increased fraction of fast ADC values compared with other subtypes $(\mathrm{P}<0.01)$ and TNBC tumor tissues $(\mathrm{P}<0.05)$. Therefore, the IVIM parameters of tumor, tumor edge and peritumor tissues in various subtypes of breast cancer may be useful for differentiation of breast cancer subtypes and to assess the invasive extent of the tumors.

\section{Introduction}

Breast cancer is a common disease in females with diverse histological subtypes and therapeutic approaches (1-3). It is important to diagnose breast cancer based on its intrinsic biological subtype $(4,5)$. Gene expression profiling may be used to classify breast cancer into molecular subtypes. However, it is not always feasible to obtain gene expression information, and different molecular subtypes of breast cancer are often evaluated by estrogen receptor (ER), progesterone receptor (PR), human epidermal growth factor receptor 2 (HER2) and Ki-67 labeling indexes using immunohistochemical methods. Tissue biopsies may provide an answer to clinical questions and provide clarity to patients, however, biopsy procedures may result in anxiety and suffering for patients. Therefore, it is necessary to differentiate various tumor subtypes with noninvasive methods (6,7). Mammography is commonly used to detect breast cancer. Mammography has a low sensitivity for dense breast tissue, but an acceptable sensitivity for mixed tissue and fatty tissue (8). Ultrasound (US), with its convenience and low cost, is becoming a common examination method for patients with breast cancer (9). It is difficult to diagnose non-mass breast cancer using US. Magnetic resonance imaging (MRI) as noninvasive method is an important radiological method for the assessment of breast cancer (10). Previous studies have demonstrated diffusion weighted imaging (DWI) to be effective at reflecting tumor cellularity and tissue organization (11-13). In aggressive tumors, increased cellularity leads to the restriction 
of water molecule movement by decreasing the extracellular space, which results in restricted diffusion in malignant tumors. Therefore, the apparent diffusion coefficient (ADC) has become a widely accepted index to assess cellularity (14-19).

Intravoxel incoherent motion (IVIM) is a useful imaging technique which can separate perfusion from diffusion via a biexponential model analysis using multiple b-values $(20,21)$. Since Le Bihan et al (21) proposed the method of IVIM, a number of studies have confirmed the effects of microcapillary perfusion using DWI (22-25). When DWI is used with multiple b-values (usually between 0 and $1,500 \mathrm{sec} / \mathrm{mm}^{2}$ for body imaging), the signal intensity at low b-values $\left(0-200 \mathrm{sec} / \mathrm{mm}^{2}\right)$ reflects microcirculation within capillaries. Alternatively, at higher b-values $\left(>200 \mathrm{sec} / \mathrm{mm}^{2}\right)$, the signal intensity is more reflective of tissue diffusivity $(24,26)$. The IVIM method is able to obtain a variety of quantitative parameters, including slow ADC, fast ADC and fraction of fast ADC values, which reflect the perfusion and diffusion information of the tissues. The ADC value achieved by the traditional DWI method does not exclude the effect of microcirculation which results in inaccurate measurement. Since the slow ADC value excludes the influence of blood perfusion, it is able to reflect the true diffuse state of water molecules, which is a more accurate measure than the traditional ADC value.

Heterogeneity is a known trait of cancer which confounds treatment planning and influences treatment efficacy $(27,28)$. Breast cancer is a heterogeneous tumor that may be observed clearly (29). It would be of benefit to the therapeutic treatment of breast cancer to quantitatively analyze the heterogeneous tumor microenvironment using IVIM parameters and study their correlation with breast cancer histological features. Previous studies have demonstrated that IVIM metrics may distinguish malignant and benign lesions (23,30,31), establish a correlation between one subtype of breast cancer and IVIM parameters $(25,32-34)$ and predict the neoadjuvant treatment response in patients with breast cancer (35). However, to the best of our knowledge, very little research has reported on the associations between IVIM parameters and the characteristics of tumor, tumor edge and surrounding tissues in different subtypes of breast cancer. Investigating the characteristics of tumor heterogeneity in the distinct regions of breast cancer may help physicians to evaluate tumors with increased accuracy. The objective of the present study is to compare IVIM parameters and the characteristics of tumor, tumor edge and surrounding tissues with regard to the histopathology and subtypes of breast cancer. An improved understanding of IVIM parameters and tumor characteristics may help identify clinically useful biomarkers to evaluate the distinct subtypes of breast cancer via noninvasive imaging.

\section{Patients and methods}

Patients. The present retrospective study was approved by the Institutional Research Board of Harbin Medical University (Harbin, China) and the requirement for informed consent was waived. A total of 141 patients underwent breast MRI at 3.0T at the Second Affiliated Hospital of Harbin Medical University between June 2015 and November 2017. Of these, 119 patients were positive for breast cancer (age range, 22-76 years; mean age, $50.2 \pm 10.5$ years) and 22 patients for benign lesions (age range, 30-62 years; mean age, $46.3 \pm 11.7$ years) (Table I). The patient inclusion criteria were as follows: i) Patients had newly diagnosed, pathologically confirmed breast cancer diagnosed using FNA. Final histopathology diagnosis was confirmed using surgically excised specimens. ii) Patients were not receiving neoadjuvant systemic treatment. iii) Follow-up for all benign lesions was performed $>2$ years and the size of lesions had not markedly changed and no new lesions were identified within the follow-up periods. iv) Breast lesions had a unifocal mass and the tumor diameter was $>1 \mathrm{~cm}$.

MRI. Imaging was performed on a $3.0 \mathrm{~T}$ system (Discovery MR750; GE Healthcare, Chicago, IL, USA) using the breast coil as a transmitter and a dedicated 8-channel phased-array receiver coil. The following scanning sequences were performed: i) A conventional scanning sequence consisting of axial T1-weighted fast-field-echoes [repetition time (TR)/echo time (TE), 492/2.3 ms; matrix, 320x256; number of signals averaged (NSA), 1; flip angle, $111^{\circ}$ ]; a sagittal T2-weighted fast-field-echoes with fat saturated (TR/TE, 3000/85 ms; matrix, 288x192; NSA, 1; flip angle, 111 ); an axial T2-weighted fast-field-echoes ideal with array spatial sensitivity encoding technique (TR/TE, 3901/85 ms; matrix, 320x256; NSA, 1; flip angle, $111^{\circ}$ ); ii) Axial DW single-shot dual spin echo sequence with echo-planar imaging readout at $9 \mathrm{~b}$-values $\left(b=0,50,100,150,200,400,500,1,000\right.$ and 1,500 sec/mm ${ }^{2}$; iii) a Dyn axial volume image breast assessment gradient echo (TR/TE, 6.4/2.3 ms; matrix, 220x320 NSA, 2; flip angle, 11 ${ }^{\circ}$; dynamics number, 8 ). At the second dynamic time acquisition, $0.2 \mathrm{mmol} / \mathrm{kg}$ body weight of gadolinium (gadodiamide and omniscan; GE Healthcare) was administered intravenously with a power injector at a rate of $2.5 \mathrm{ml} / \mathrm{s}$, followed by a bolus injection of $20 \mathrm{ml}$ saline flush.

Histopathological analysis. Immunohistochemistry analyses were performed for ER, PR and HER2 expression, and the Ki-67 labeling index. Tissues were cut and fixed in $10 \%$ neutral buffered formalin (Beijing Yili Fine Chemicals Co., Ltd.; Beijing, China) at room temperature for $24 \mathrm{~h}$. Paraffin-embedded tissue sections $(4 \mu \mathrm{m})$ were deparaffinized at $58^{\circ} \mathrm{C}$ for $120 \mathrm{~min}$ and then with $100 \%$ dimethylbenzene at room temperature for 10 min three times; after that the sections were rehydrated with $100 \%$ alcohol at room temperature for 5 min twice and then $95 \%$ alcohol at room temperature for 5 min twice, and finally $80 \%$ alcohol at room temperature for $5 \mathrm{~min}$ once. Antigen retrieval was performed by heating the sections in a $95^{\circ} \mathrm{C}$ water bath in the presence of EDTA in a microwave for $5 \mathrm{~min}$. Tissue sections were treated with $0.3 \%$ hydrogen peroxide in methanol (Beyotime Institute of Biotechnology, Inc., Haimen, China) for $15 \mathrm{~min}$ at room temperature, to eliminate endogenous peroxidase activity. Following three washes of 5 min with phosphate-buffered saline (PBS; Beyotime Institute of Biotechnology, Inc.), the tissue sections were incubated with rabbit anti-human ER polyclonal antibody (1:400 dilution; cat. no. AA110; Beyotime Institute of Biotechnology, Inc) at room temperature for $60 \mathrm{~min}$. Following three washes of 5 min with PBS, the slides were incubated with an horseradish peroxidase-conjugated goat anti-rabbit IgG (1:50 dilution; cat. no. A0208; Beyotime Institute of Biotechnology, Inc) at $37^{\circ} \mathrm{C}$ for $30 \mathrm{~min}$. Following three washes of $5 \mathrm{~min}$ with PBS, a 
Table I. Clinical data for patients enrolled in this study.

\begin{tabular}{|c|c|}
\hline Clinical characteristics & Number of patients \\
\hline Benign & 22 \\
\hline Cancer & 119 \\
\hline Total & 141 \\
\hline \multicolumn{2}{|c|}{$\begin{array}{l}\text { Histopathological features and } \\
\text { molecular prognostic factors }\end{array}$} \\
\hline \multicolumn{2}{|l|}{ Lymph node metastases } \\
\hline Positive & 89 \\
\hline Negative & 30 \\
\hline \multicolumn{2}{|l|}{$\mathrm{Ki}-67$} \\
\hline$\geq 14 \%$ & 86 \\
\hline$<14 \%$ & 33 \\
\hline \multicolumn{2}{|l|}{ ER } \\
\hline Positive & 72 \\
\hline Negative & 47 \\
\hline \multicolumn{2}{|l|}{$\mathrm{PR}$} \\
\hline Positive & 60 \\
\hline Negative & 59 \\
\hline \multicolumn{2}{|l|}{ HER2 } \\
\hline Positive & 33 \\
\hline Negative & 86 \\
\hline \multicolumn{2}{|l|}{ Molecular subtype } \\
\hline Luminal A & 22 \\
\hline Luminal B (HER2+) & 30 \\
\hline Luminal B (HER2-) & 20 \\
\hline HER2 & 22 \\
\hline TNBC & 25 \\
\hline
\end{tabular}

ER, estrogen receptor; PR, progesterone receptor; HER2, human epidermal growth factor receptor 2; TNBC, triple-negative breast cancer.

3,3'-diaminobenzidine detection kit (PV9000; ZSGB-BIO, Beijing, China) was used for color development, according to the manufacturer's protocol. Images were captured and analyzed by K-Viewer software (version 1.5.2.5, KFBIO Co., Nigbo, China; http://www.kfbio.cn). Immunohistochemistry processes for PR, HER2 and Ki-67 were similar to that of ER, and relative specific antibodies including rabbit anti-human PR polyclonal antibody (1:200 dilution; cat. no. AF0165; Beyotime Institute of Biotechnology, Inc), rabbit anti-human HER2 polyclonal antibody (1:200 dilution; cat. no. AF0177; Beyotime Institute of Biotechnology, Inc), rabbit anti-human Ki-67 polyclonal antibody (1:100 dilution; cat. no. AF1738; Beyotime Institute of Biotechnology, Inc) at room temperature for $60 \mathrm{~min}$. ER or PR was defined as positive if the positive cell percentage was $\geq 10 \%$, and as negative if it was $<10 \%$. HER2 expression was analyzed according to the American Society of Clinical Oncology (ASCO)/College of American Pathologists HER2 test guidelines (36). Immunohistochemical analyses were performed by experienced breast pathologist in pathology center of the Second Affiliated Hospital of Harbin Medical University. HER 2 expression was scored as $0,1+, 2+$, or $3+$ by immunohistochemical analysis. According to the American Society of Clinical Oncology (ASCO)/College of American Pathologists HER 2 test guidelines (36), scores of 0 and $1+$ were considered as HER 2 negative, and scores of $3+$ were considered as positive. For samples with HER 2 expression graded 2+, gene amplification by fluorescence in situ hybridization (FISH) was used to determine HER2 status. In the present study, FISH analysis was used to analyze HER2 DNA in breast tumor tissues using a (HER-2 DNA probe kit, 06N46, VYSIS; Abbott Pharmaceutical Co. Ltd., Lake Bluff, IL, USA). The procedures were conducted according to the manufacturer's protocol. The paraffin-embedded tissue sections $(4 \mu \mathrm{m})$ were baked overnight at $56^{\circ} \mathrm{C}$. Subsequently, the paraffin was removed from the sections with a 10 min washing in $100 \%$ Hemo-De (cat. no. C14634100, Shanghai Haling Biotechnology Co., Ltd.) at room temperature twice. The sections were dehydrated twice in 100\% ethanol for $5 \mathrm{~min}$ and then dried at room temperature. The sections were digested by proteinase (C122917; ShangHai Rebiosci Biotechnology Co., Ltd) which concentration was $100 \mu \mathrm{g} / \mathrm{ml}$ at $37^{\circ} \mathrm{C}$ for $45 \mathrm{~min}$. The sections were washed with a stringency of $2 \mathrm{X}$ saline sodium citrate (SSC) for $5 \mathrm{~min}$ and then dried. Next, $10 \mu 1$ PathVysion ${ }^{\circledR}$ probe in HER-2 DNA probe kit was applied to the sections. The sections were coverslipped, sealed with rubber cement, and the sections were then denatured for $5 \mathrm{~min}$ at $73^{\circ} \mathrm{C}$ and allowed to hybridize overnight at $37^{\circ} \mathrm{C}$. The coverslip was carefully removed in a $2 \mathrm{X}$ $\mathrm{SSC} / 0.3 \% \mathrm{NP}-40$ solution (included in the HER-2 DNA probe kit), and the sections were washed in $2 \mathrm{X} \mathrm{SSC} / 0.3 \% \mathrm{NP}-40$ for $5 \mathrm{~min}$. The sections were carefully incubated in a $2 \mathrm{X} \mathrm{SSC} / 0.3 \%$ NP-40 solution at $73^{\circ} \mathrm{C}$ for $2 \mathrm{~min}$, and then washed in $2 \mathrm{X}$ $\mathrm{SSC} / 0.3 \% \mathrm{NP}-40$ solution for $5 \mathrm{~min}$ at room temperature. The sections were air-dried in the dark and then counterstained with $10 \mu 1$ 4',6-diamidino-2-phenylindole (DAPI; cat. no. C1002; Beyotime Institute of Biotechnology, Inc.) for $15 \mathrm{~min}$ at room temperature. According to the American Society of Clinical Oncology (ASCO)/College of American Pathologists HER2 test guidelines (36), gene amplification was evaluated as present when the HER2/CEP17 ratio was $\geq 2$. In the evaluation of the Ki-67 labeling index, nuclei of $\geq 14 \%$ were considered as a high value (3). Breast cancer subtypes were defined by clinicopathological criteria using molecular prognostic factors including ER, PR, HER2 and Ki-67 states. Luminal A was defined as ER and/or PR positive, HER2 negative, Ki-67 low; Luminal B (HER2-negative) was defined as ER and/or PR positive, HER2 negative, Ki-67 high. Luminal B (HER2-positive) was defined as ER and/or PR positive, HER2 overexpressed. HER2+ was defined as HER 2 over-expressed, ER and PR negative. Triple-negative breast cancer (TNBC) was defined as ER, PR and HER2 negative (4).

Microvessel density (MVD) result determination. Left and right orientation marks were made once the tumor was resected. The largest section of the tumor in the left and right direction was selected to make a pathological section, which was consistent with the MRI as far as possible. The mass was immunohistochemically stained. Tissues were cut and fixed in $10 \%$ neutral buffered formalin (Beijing Yili Fine Chemicals Co., Ltd.; Beijing, China) at room temperature for $24 \mathrm{~h}$. Paraffin-embedded tissue sections ( $4 \mu \mathrm{m})$ were deparaffinized, at $58^{\circ} \mathrm{C}$ for $120 \mathrm{~min}$ and then with $100 \%$ dimethylbenzene at room temperature for $10 \mathrm{~min}$ three times; after that the sections were rehydrated with $100 \%$ alcohol at room temperature for $5 \mathrm{~min}$ twice and then $95 \%$ alcohol at room temperature for 5 min twice, finally $80 \%$ alcohol at room temperature for $5 \mathrm{~min}$. Antigen retrieval was performed by heating the sections in a $95^{\circ} \mathrm{C}$ water bath in the presence of EDTA in a microwave 
for $5 \mathrm{~min}$. Tissue sections were treated with $0.3 \%$ hydrogen peroxide in methanol (Beyotime Institute of Biotechnology, Inc., China) for $15 \mathrm{~min}$ at room temperature, to eliminate endogenous peroxidase activity. Following three washes of 5 min with phosphate-buffered saline (PBS; Beyotime Institute of Biotechnology, Inc.), the tissue sections were incubated with rabbit anti-human CD34 polyclonal antibody (1:300 dilution; cat. no. AF0102; Beyotime Institute of Biotechnology, Inc) at room temperature for $60 \mathrm{~min}$. Following three washes of 5 min with PBS, the slides were incubated with an horseradish peroxidase-conjugated goat anti-rabbit IgG (1:50 dilution; cat. no. A0208; Beyotime Institute of Biotechnology, Inc) at $37^{\circ} \mathrm{C}$ for $30 \mathrm{~min}$. Following three washes of $5 \mathrm{~min}$ with PBS, a 3,3'-diaminobenzidine detection kit (PV9000; ZSGB-BIO, China) was used for color development, according to the manufacturer's protocol. Images were captured and analyzed by K-Viewer software (version 1.5.2.5; KFBIO; http://www. kfbio.cn). A double-blind analysis was performed by experienced pathologists in the pathology center of the Second Affiliated Hospital of Harbin Medical University. If they were in disagreement, consultations were performed to draw a consensus conclusion as to the final results. The MVD count standard was based on the method reported by Weidner (37). Weidner (37) reported brown-staining cytoplasm or cell membrane, clearly separate from connective tissue elements, rather than low background staining were treated as the criteria for positive endothelial cells. According to the method described by Weidner (37), endothelial cell clusters forming lumen or vessels were counted as individual microvessels. However, a luminal area larger than the sum of the diameters of 8 erythrocytes, or a blood vessel with a thick muscular layer were not counted as microvessels. The pathological sections were observed using a low magnification light microscopy (magnification, x100) to find three areas of high blood vessel density where more stained vessels were presented as a hotspot area. These areas were consisted with the same direction of the MRI at the largest section of the tumor in the left and right direction to the maximum extent. In addition, the high blood vessel density areas were selected in both pathological sections and MRI which also made the results objectively. Subsequent to finding the hotspot area, the number of blood vessels stained with CD34 was counted using a high magnification light microscopy (magnification, x200). Finally, the mean value of MVD in the three hot spots was calculated as the MVD value of the tumor.

IVIM analysis and region of interest (ROI) selection. All images were reviewed by a breast radiologist (a member of research group) who was blinded to the histopathological results. The IVIM data were analyzed using a GE AW4.6 workstation (version 9.4.05; GE Healthcare), using the biexponential model of Le Bihan et al $(21,23)$. The equation used was as follows:

$$
\mathrm{S}_{\mathrm{b}} / \mathrm{S}_{0}=(1-\mathrm{f}) \exp (-\mathrm{bD})+\mathrm{f} \exp \left[-\mathrm{b}\left(\mathrm{D}^{*}+\mathrm{D}\right)\right]
$$

Where $S_{b}$ is the signal intensity in the pixel with diffusion gradient $b, S_{0}$ is the signal intensity without diffusion gradient, $\mathrm{D}$ is the true diffusion which is expressed by slow ADC in this study, $\mathrm{D}^{*}$ which is expressed by fast ADC is the pseudo-diffusion coefficient and $\mathrm{f}$ which is expressed by fraction of fast ADC is the perfusion fraction associated with microcirculation. The IVIM parameters were calculated based on the assumption that $\mathrm{D}^{*}$ was significantly larger than $\mathrm{D}$ and the effects of $\mathrm{D}^{*}$ on the signal decay at large $\mathrm{b}$-values $\left(>200 \mathrm{sec} / \mathrm{mm}^{2}\right)$ can be neglected (38). That is the signal intensity at low b-values $\left(0-200 \mathrm{sec} / \mathrm{mm}^{2}\right)$ reflects microcirculation within capillaries and higher b-values $\left(>200 \mathrm{sec} / \mathrm{mm}^{2}\right)$, the signal intensity is more reflective of tissue diffusivity $(24,26)$. This study selected b-values $(0,50,100,150,200,400,500$, 1,000 and $1,500 \mathrm{sec} / \mathrm{mm}^{2}$ ), which were used to assess breast lesions. The more b-values were selected, the longer examination times were spent. According to literature (24), the choice of muti-b values which we chosen is not only acceptable for examination times, but also can be evaluated for lesions.

The region of interest (ROI) was drawn on the slice with the largest area of breast cancer or benign lesion enclosing the entire lesion. The ROI was also placed on the highest fraction of fast ADC area at the edge of breast cancer [ROI area, <one third of tumor diameter]. The ROI of the surrounding peritumor area was measured three times at the largest area of the tumor and the mean value was calculated 1-2 cm away from the margin of the tumor entity with an area $<10 \mathrm{~mm}^{2}$. A region of ipsilateral fibroglandular tissue was sampled away from the tumor as far as possible while avoiding gross fat.

Statistical analysis. Statistical analyses were performed using SPSS software (version 21; IBM Corp., Armonk, NY, USA). Data are presented as the mean \pm standard deviation. Comparison of IVIM parameters between cancer and benign lesions, and peritumor and ipsilateral distance fibroglandular tissues were performed using a Mann-Whitney U test. The receiver operating characteristic (ROC) curve was used to compare the sensitivities and specificities of different IVIM parameters between patients with breast cancer and benign breast lesions, with the area under the ROC curve (AUC) computed and the threshold values determined by the Youden Index. Mann-Whitney $\mathrm{U}$ tests and Kruskal-Wallis $\mathrm{H}$ tests were used to compare molecular subtypes of breast cancer or molecular prognostic factors (positive versus negative) with IVIM parameters measured by each imaging. Nemenyi's test was used to compare IVIM parameters between different subtypes and different regions of breast cancer following Kruskal-Wallis $\mathrm{H}$ tests. The ROC curve was used to compare the diagnostic efficacy of IVIM parameters in different subtypes of breast cancer. The Spearman's correlation coefficient analysis was used to analyze the correlation between molecular prognostic factors and IVIM parameters. Comparisons of MVD between different ER and HER2 status in tumor tissues of breast cancer were performed using unpaired t-tests. $\mathrm{P}<0.05$ was considered to indicate a statistically significant difference.

\section{Results}

Patients and histopathology. Clinical data for patients are summarized in Table I. The 119 patients with breast cancer consisted of 10 ductal carcinoma in situ (DCIS) cases, 9 invasive lobular carcinoma cases, 26 invasive carcinomas of no special type with DCIS, and the remaining 74 were invasive carcinomas of no special type. Benign lesion classifications 
Table II. Comparison of ADC and intravoxel incoherent motion parameters in breast cancer and benign breast lesions.

\begin{tabular}{lccc}
\hline Parameter & Cancer & Benign lesion & P-value \\
\hline ADC $\left(\times 10^{-3} \mathrm{~mm}^{2} / \mathrm{sec}\right)$ & $0.89 \pm 0.33$ & $1.69 \pm 0.42$ & $<0.001$ \\
Slow ADC $\left(\times 10^{-3} \mathrm{~mm}^{2} / \mathrm{sec}\right)$ & $0.75 \pm 0.38$ & $1.51 \pm 0.31$ & $<0.001$ \\
Fast ADC $\left(\mathrm{x} 10^{-3} \mathrm{~mm}^{2} / \mathrm{sec}\right)$ & $41.01 \pm 20.63$ & $54.20 \pm 21.25$ & $<0.001$ \\
Fraction of fast ADC $(\%)$ & $33.05 \pm 11.53$ & $17.76 \pm 7.74$ & $<0.001$ \\
\hline
\end{tabular}

ADC, apparent diffusion coefficient.

Table III. The AUC, threshold, sensitivity and specificity of ADC, slow ADC fast $\mathrm{ADC}$ and fraction of fast $\mathrm{ADC}$ values to differentiate breast cancer from benign lesions.

\begin{tabular}{lcccc}
\hline Parameter & AUC & Threshold & Sensitivity & Specificity \\
\hline ADC $\left(\times 10^{-3} \mathrm{~mm}^{2} / \mathrm{sec}\right)$ & 0.900 & 1.15 & 0.857 & 0.893 \\
Slow ADC $\left(\times 10^{-3} \mathrm{~mm}^{2} / \mathrm{sec}\right)$ & 0.920 & 1.09 & 0.929 & 0.880 \\
Fast ADC $\left(\times 10^{-3} \mathrm{~mm}^{2} / \mathrm{sec}\right)$ & 0.674 & 43.18 & 0.714 & 0.547 \\
Fraction of fast ADC $(\%)$ & 0.885 & 20.30 & 0.857 & 0.893 \\
\hline
\end{tabular}

AUC, area under the curve; ADC, apparent diffusion coefficient.

included fibrocystic change $(n=8)$, intraductal papilloma $(n=4)$, fibroadenomas $(n=6)$, and other benign lesions $(n=4)$. Histopathological features, molecular prognostic factors and molecular subtypes were used for evaluating breast cancer.

Benign lesions vs. cancer. Comparisons of ADC and IVIM parameters between patients with breast cancer and benign breast lesions are listed in Table II. Compared with benign breast lesions, the ADC, slow ADC and fast ADC values were significantly decreased for patients with breast cancer $(\mathrm{P}<0.001)$. Patients with breast cancer also exhibited a significantly increased fraction of fast ADC value compared with those with benign breast lesions $(\mathrm{P}<0.001)$. The AUC sensitivity and specificity threshold values to distinguish breast cancer from benign breast lesions using the ADC, slow $\mathrm{ADC}$, fast $\mathrm{ADC}$ and fraction of fast ADC values are presented in Table III. The slow ADC value was revealed to have the highest AUC (0.920).

Histopathological features comparison. The ADC, slow ADC, fast ADC and fraction of fast ADC values of tumor, tumor edge and peritumor tissues in different histopathological features are listed in Table IV. Tumor tissues with metastatic axillary lymph nodes exhibited significantly increased fraction of fast ADC values $(\mathrm{P}<0.001)$ and decreased slow $\mathrm{ADC}$ values $(\mathrm{P}=0.006)$, compared with tumor entities without metastatic axillary lymph nodes. The Fast ADC values of tumor entities in ER and PR negative groups were increased compared with positive groups $(\mathrm{P}<0.001)$, and the slow ADC values of tumor entities were lower in ER and PR negative groups compared with positive groups $(\mathrm{P}<0.001)$. The present study demonstrated that HER2 positive tumor tissues exhibited an increased fraction of fast ADC value compared with the HER2 negative group $(\mathrm{P}<0.001)$, whereas compared with the HER2 negative group, a significant decrease was observed in the fraction of fast ADC values of HER2 positive tumor edge $(\mathrm{P}=0.006)$ and peritumor

is

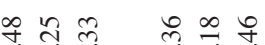

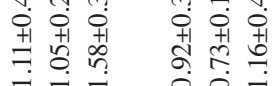

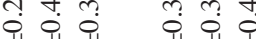

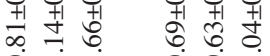

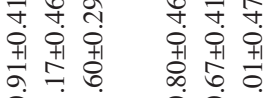

○) $\stackrel{m}{\circ}$

茾完吕

†.

0 - 0 O

过艺

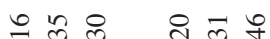

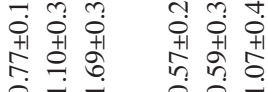

チฯ $\mathscr{2}$

भ

ํำ

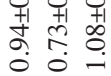

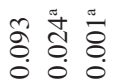

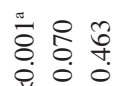

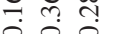

?.

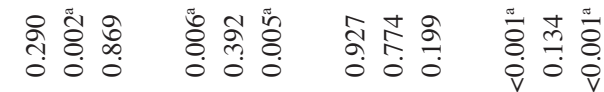

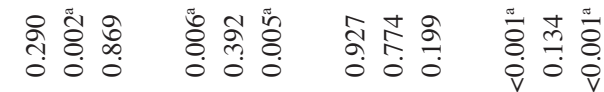

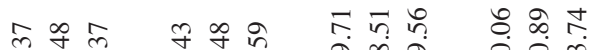

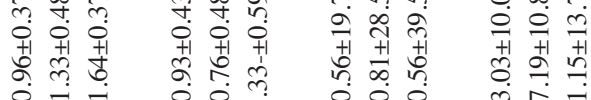

ஸे

ले ले पे ते ले क्षे थे के ले

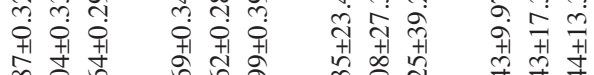

क

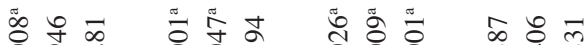

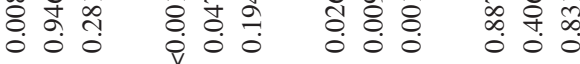

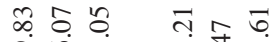

वे

त $\begin{array}{ll}+1 \\ \text { मे }\end{array}$

लें ले कें के

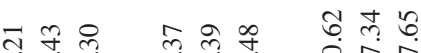

तु

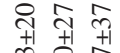

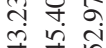

$\stackrel{ }{+1} \frac{m}{+1} \frac{n}{+1}$

ले 孚

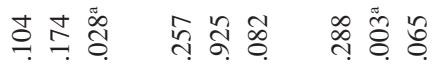

ॠ

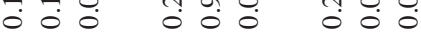

₹

iो กิ

a $\begin{gathered}2 \\ +1 \\ +1\end{gathered}$

$\infty$ mे

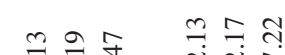

สิ สำ

苟

寸

लें

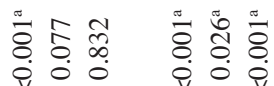

वे

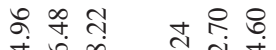

茾

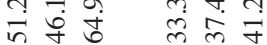

nก $\cong$

กั

ก

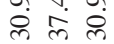

으는

$\ddot{m} \dot{\square}$

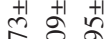

लें के

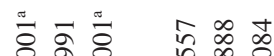

จ

ñ

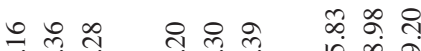

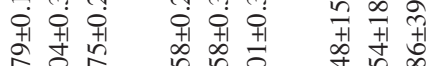

in $\overbrace{}^{\infty}$

๓ 9.

齐

ले

아의 음 훙

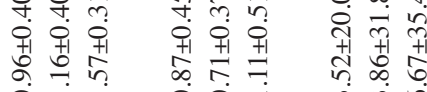

๙

$\stackrel{i}{i} \stackrel{+}{+1}$

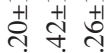

ते ले ले 
Table V. Immunohistochemical differences of MVD in tumor tissues with distinct histopathological features.

\begin{tabular}{lcccr}
\hline & ER+ & ER- & P-value & HER2+ \\
\hline MVD, number & $23.52 \pm 17.08$ & $31.57 \pm 11.23$ & $0.002^{\mathrm{a}}$ & $33.48 \pm 22.32$ \\
\hline
\end{tabular}

aP<0.05. MVD, microvessel density; ER, estrogen receptor; PR, progesterone receptor; HER2, human epidermal growth factor receptor 2.
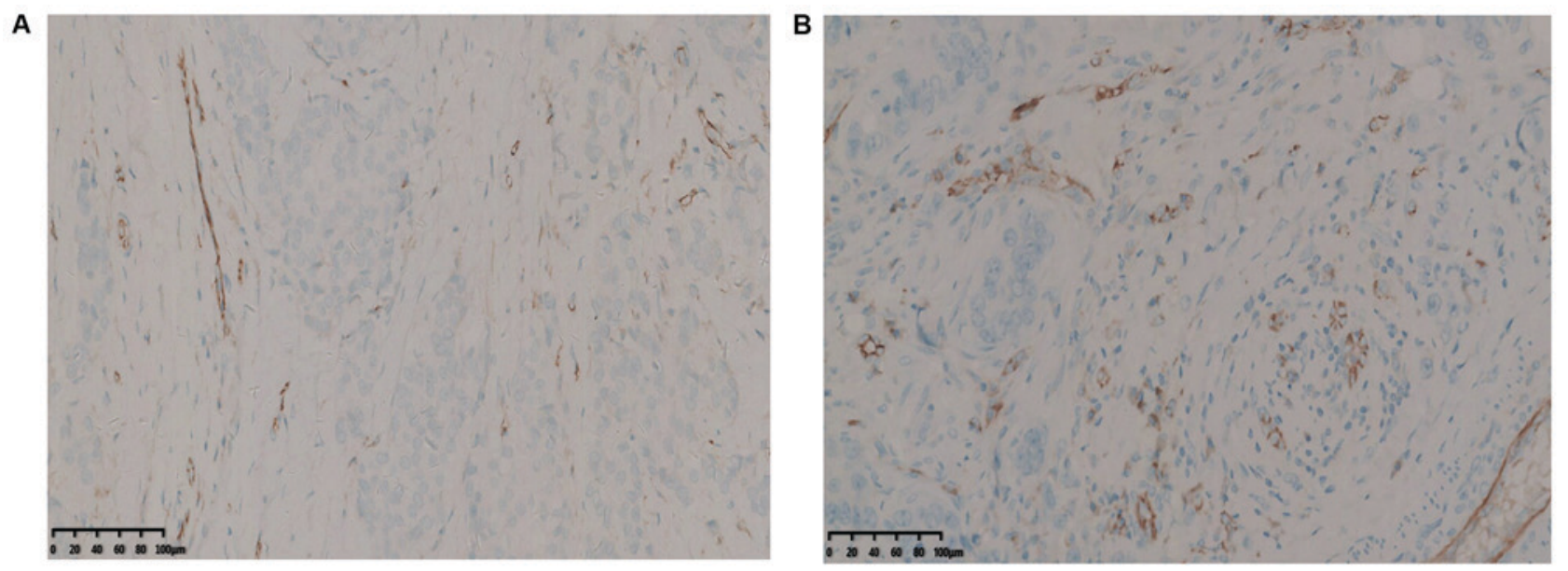

Figure 1. MVD of ER and HER2 status in breast cancer tumor tissues. (A) MVD of ER positive and HER2 negative breast cancer; (B) MVD of ER negative and HER2 positive breast cancer. (Magnification, x200) MVD, microvessel density; ER, estrogen receptor; HER2, human epidermal growth factor receptor 2.

tissues $(\mathrm{P}=0.001)$. The slow ADC value of tumor tissues was decreased $(\mathrm{P}<0.001)$ and the fast ADC value of tumor tissues was increased $(\mathrm{P}=0.026)$ in the high $\mathrm{Ki}-67$ group, compared with the low Ki-67 group. Immunohistochemical analysis of the ER and HER2 status in tumor tissues of breast cancer are presented in Table $\mathrm{V}$ and Fig. 1.

The slow ADC value of tumor tissues exhibited a negative correlation $(r=-0.332, \mathrm{P}<0.001)$ and fraction of fast ADC of tumor entities demonstrated a positive correlation $(r=0.309$, $\mathrm{P}=0.009$ ) with $\mathrm{Ki}-67$ expression (Table VI). The fast ADC value of tumor entities identified a negative correlation with ER $(r=-0.506, P<0.001)$ and $P R(r=-0.552, P<0.001)$ positive samples (Table VI).

Subtypes comparison. Comparison of the ADC, slow $\mathrm{ADC}$, fast ADC and fraction of fast ADC values of tumor, tumor edge and peritumor tissues with distinct subtypes are presented in Tables VII-IX and Fig. 2. Luminal A tumor tissue demonstrated increased slow ADC $(\mathrm{P}<0.001)$ and decreased fast ADC $(\mathrm{P}<0.001)$ values compared with other subtypes. The ROC curve used to distinguish between Luminal A and non-Luminal A cancer using the ADC, slow ADC and fast ADC values of tumor entity is presented in Fig. 3. The AUC of sensitivity and specificity threshold values for ADC, slow ADC and fast ADC values of tumor tissues are listed in Table X. Luminal B (HER2-negative) samples demonstrated decreased fraction of fast ADC values compared with other subtypes in tumor $(\mathrm{P}<0.001)$ and peritumor $(\mathrm{P}<0.001)$ tissues. The ROC curve that used to distinguish between Luminal B (HER2-negative) and Luminal B (HER2-positive) using the fraction of fast ADC value of tumor tissues is presented in Fig. 3. With a threshold value of 28.15, the AUC using the fraction of fast ADC to distinguish between Luminal B
(HER2-negative) and Luminal B (HER2-positive) was 0.800, the sensitivity was 0.800 and the specificity was 0.667 . TNBC tumor tissue demonstrated a decreased slow ADC value $(\mathrm{P}<0.001)$, increased fast ADC value $(\mathrm{P}<0.001)$ and increased fraction of fast ADC value $(\mathrm{P}<0.001)$ compared with other subtypes. The tumor edge tissue of TNBC demonstrated an increased fraction of fast ADC value compared with other subtypes $(\mathrm{P}=0.001)$ and TNBC tumor tissue $(\mathrm{P}=0.015)$. The peritumor tissue of TNBC exhibited an increased fast ADC value compared with other subtypes $(\mathrm{P}=0.001)$. The ROC curve that was used to distinguish between TNBC and non-TNBC using ADC, slow ADC, fast ADC and fraction of fast ADC of tumor tissues is presented in Fig. 3. The AUC sensitivity and specificity threshold values for ADC, slow ADC, fast ADC and fraction of fast ADC of tumor tissues are listed in Table XI. Representative images are presented in Fig. 4 for Luminal B (HER2-positive) cancer. There were significant differences in IVIM parameters between the peritumor area tissues and ipsilateral distance fibroglandular tissues (Table XII). There were no significant differences in IVIM parameters between ipsilateral distance fibroglandular tissues of different subtypes breast cancer $(\mathrm{P}>0.05)$.

\section{Discussion}

The present study illustrated the spatial heterogeneity observed in angiogenesis and cellularity through IVIM parameters, which were able to classify subtypes of breast cancer and distinguish malignant tumors from benign lesions. The IVIM parameters of tumor, tumor edge and peritumor tissues were investigated with regard to distinct histopathological features and subtypes. The results demonstrated IVIM technology was a useful method to differentiate a number of breast cancer 
Table VI. Spearman's correlation between the ADC, slow ADC, fast ADC and fraction of fast ADC values of tumor tissues and the histopathological features.

\begin{tabular}{|c|c|c|c|c|c|c|c|c|}
\hline \multirow[b]{2}{*}{ Variable } & \multicolumn{2}{|c|}{$\mathrm{ADC}\left(\mathrm{x} 10^{-3} \mathrm{~mm}^{2} / \mathrm{sec}\right)$} & \multicolumn{2}{|c|}{ Slow $\operatorname{ADC}\left(\times 10^{-3} \mathrm{~mm}^{2} / \mathrm{sec}\right)$} & \multicolumn{2}{|c|}{ Fast $\mathrm{ADC}\left(\mathrm{x} 10^{-3} \mathrm{~mm}^{2} / \mathrm{sec}\right)$} & \multicolumn{2}{|c|}{ Fraction of fast ADC (\%) } \\
\hline & R-value & P-value & R-value & P-value & $\mathrm{R}$-value & P-value & R-value & P-value \\
\hline Ki-67 & -0.243 & $0.008^{\mathrm{a}}$ & -0.332 & $<0.001^{\mathrm{a}}$ & 0.182 & 0.119 & 0.309 & $0.009^{\mathrm{a}}$ \\
\hline ER+ & 0.154 & 0.094 & 0.370 & $<0.001^{\mathrm{a}}$ & -0.506 & $<0.001^{\mathrm{a}}$ & -0.054 & 0.559 \\
\hline $\mathrm{PR}+$ & 0.264 & $0.004^{\mathrm{a}}$ & 0.504 & $<0.001^{\mathrm{a}}$ & -0.552 & $<0.001^{\mathrm{a}}$ & -0.006 & 0.949 \\
\hline HER 2+ & -0.150 & 0.105 & -1.040 & 0.258 & 0.098 & 0.290 & -0.625 & $<0.001^{\mathrm{a}}$ \\
\hline
\end{tabular}

${ }^{\mathrm{a}} \mathrm{P}<0.05$. ADC, apparent diffusion coefficient; ER, estrogen receptor; PR, progesterone receptor; HER2, human epidermal growth factor receptor 2.
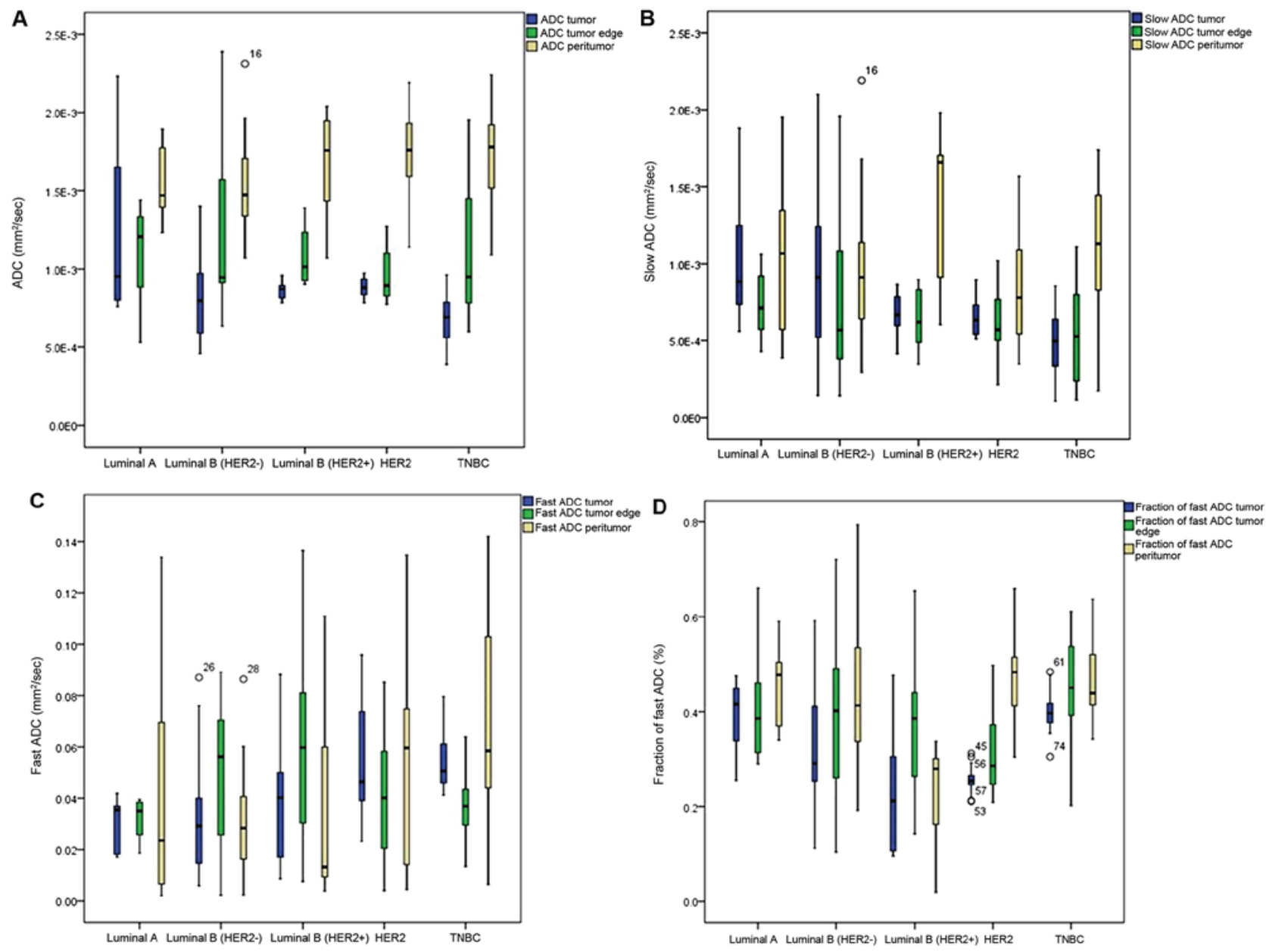

Figure 2. Box plots of ADC, slow ADC, fast ADC and fraction of fast ADC values of tumor, tumor edge and peritumor tissues in breast cancer subtypes. (A) ADC. (B) Slow ADC. (C) Fast ADC. (D) Fraction of fast ADC. The top and bottom lines of the box represent the 25-75th percentile values, the line in the box represents the median value, the lines outer bars represent maximum and minimum values and circle represent possible outlier value. ADC, apparent diffusion coefficient; HER2, human epidermal growth factor receptor 2; TNBC, triple-negative breast cancer.

subtypes, assess the invasive extent of the tumor and distinguish malignant tumors from benign lesions. To the best of our knowledge, this is the first study demonstrating that the IVIM parameters of tumor edge and peritumor tissues were able to differentiate breast cancer subtypes and assess the invasive extent of tumors.

The present study demonstrated that ADC and slow ADC values were significantly increased and the fraction of fast ADC value was decreased in benign lesions compared with breast cancer, which was consistent with most previous studies $(30,31,39)$. This was used to distinguish breast cancer from benign breast lesions using ADC. It has been demonstrated that cellularity and microcirculation influence ADC measurements (31). Breast cancer exhibited high cellularity (low diffusivity) and high vascularity (high perfusion) (32). The slow ADC value achieved by IVIM avoids the influence of microcirculation, thus quantifying cellularity more precisely. There was a difference between the ADC and slow ADC values which indicated that the microcirculation may also contribute to the ADC value. Breast cancer is more cellular and vascular than benign lesions, thus breast cancer tumors exhibit decreased slow ADC and increased fraction of 
(1)

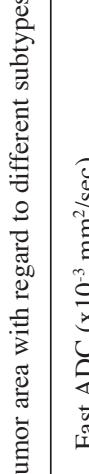

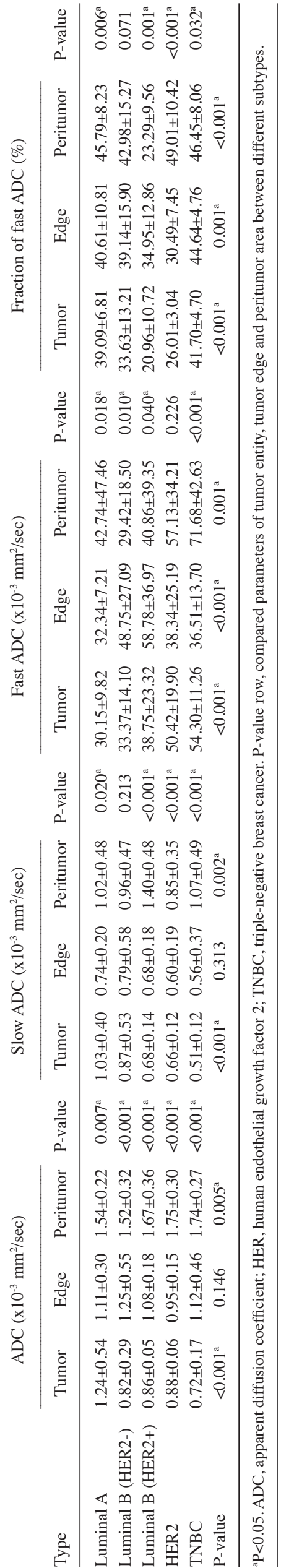

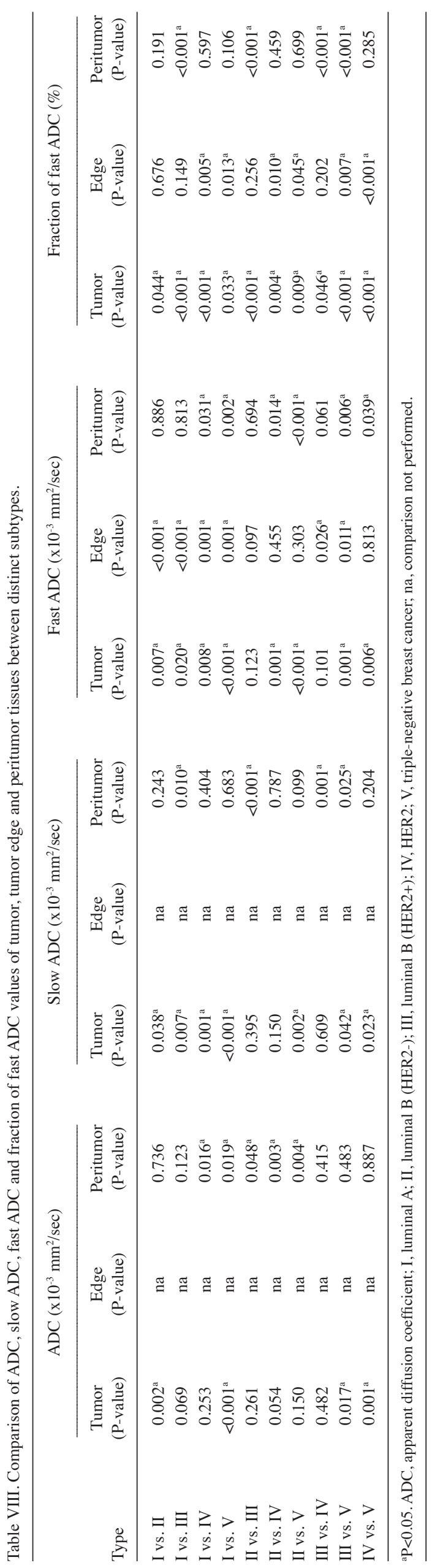




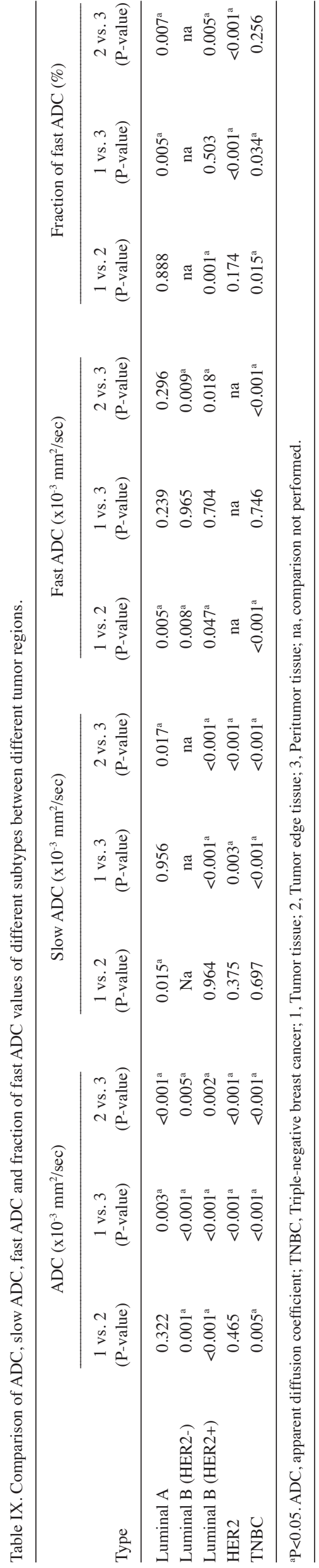

Table X. The AUC, threshold, sensitivity and specificity of ADC, slow ADC and fast ADC values of tumor tissues to distinguish between Luminal A and non-Luminal A cancer.

\begin{tabular}{lcccc}
\hline Parameter & AUC & Threshold & Sensitivity & Specificity \\
\hline ADC $\left(\times 10^{-3} \mathrm{~mm}^{2} / \mathrm{sec}\right)$ & 0.731 & 0.85 & 0.727 & 0.526 \\
Slow ADC $\left(\times 10^{-3} \mathrm{~mm}^{2} / \mathrm{sec}\right)$ & 0.774 & 0.79 & 0.773 & 0.711 \\
Fast ADC $(\%)$ & 0.605 & 26.77 & 0.682 & 0.598 \\
\hline
\end{tabular}

AUC, area under the curve; ADC, apparent diffusion coefficient.

Table XI. The AUC, threshold, sensitivity and specificity of ADC, slow ADC, fast $\mathrm{ADC}$ and fraction of fast $\mathrm{ADC}$ values of tumor entity to distinguish between TNBC and non-TNBC.

\begin{tabular}{lcccc}
\hline Parameter & AUC & Threshold & Sensitivity & Specificity \\
\hline ADC $\left(\times 10^{-3} \mathrm{~mm}^{2} / \mathrm{sec}\right)$ & 0.742 & 0.80 & 0.760 & 0.777 \\
Slow ADC $\left(\times 10^{-3} \mathrm{~mm}^{2} / \mathrm{sec}\right)$ & 0.858 & 0.59 & 0.760 & 0.819 \\
Fast ADC $\left(\times 10^{-3} \mathrm{~mm}^{2} / \mathrm{sec}\right)$ & 0.869 & 47.85 & 0.800 & 0.851 \\
Fraction of fast ADC $(\%)$ & 0.784 & 39.15 & 0.760 & 0.723
\end{tabular}

AUC, area under the curve; ADC, apparent diffusion coefficient; TNBC, triple-negative breast cancer.

Table XII. Comparison of ADC, slow ADC, fast ADC and fraction of fast $\mathrm{ADC}$ values of peritumor area and ipsilateral distance fibroglandular tissue.

\begin{tabular}{lccr}
\hline Parameter & Peritumor & Fibroglandular tissue & P-value \\
\hline ADC $\left(\times 10^{-3} \mathrm{~mm}^{2} / \mathrm{sec}\right)$ & $1.64 \pm 0.31$ & $2.24 \pm 2.04$ & $<0.001^{\mathrm{a}}$ \\
Slow ADC $\left(\times 10^{-3} \mathrm{~mm}^{2} / \mathrm{sec}\right)$ & $1.07 \pm 0.47$ & $1.26 \pm 0.52$ & $0.007^{\mathrm{a}}$ \\
Fast ADC $\left(\times 10^{-3} \mathrm{~mm}^{2} / \mathrm{sec}\right)$ & $47.80 \pm 39.47$ & $66.25 \pm 53.59$ & $<0.001^{\mathrm{a}}$ \\
Fraction of Fast ADC $(\%)$ & $41.09 \pm 14.62$ & $35.79 \pm 11.53$ & $0.002^{\mathrm{a}}$ \\
\hline
\end{tabular}

${ }^{\mathrm{a}} \mathrm{P}<0.05$. ADC, apparent diffusion coefficient; fibroglandular tissue, ipsilateral distance fibroglandular tissue.

fast ADC values compared with benign lesions. Fast ADC was identified to be decreased in breast cancer tissues compared with benign breast lesions; a result which was consistent with previous studies $(23,39,40)$. The fast ADC value was considered proportional to the average blood velocity and capillary segment length, and it has been demonstrated that the fraction of fast ADC value reflects vascular density (41). Compared with benign lesions, the fast ADC value of breast cancer was decreased which may be associated with a reduced blood flow owing to increased cellular proliferation. IVIM parameters can reflect microcirculation and cellularity of the tumor, which can provide a more accurate differential diagnosis than DWI. The ROC curve analysis demonstrated that significant differentiation between breast cancer and benign breast lesions was provided by the slow ADC and fraction of fast ADC values with more accuracy than ADC alone.

In the present study, certain parameters observed by IVIM exhibited significant differences between various tumor subtypes, categorized via distinct ER, PR and HER2 expression levels. Previous studies have reported the associations between ADC values and prognostic factors in breast cancer $(31,42,43)$. The present results indicated that increased slow ADC and 

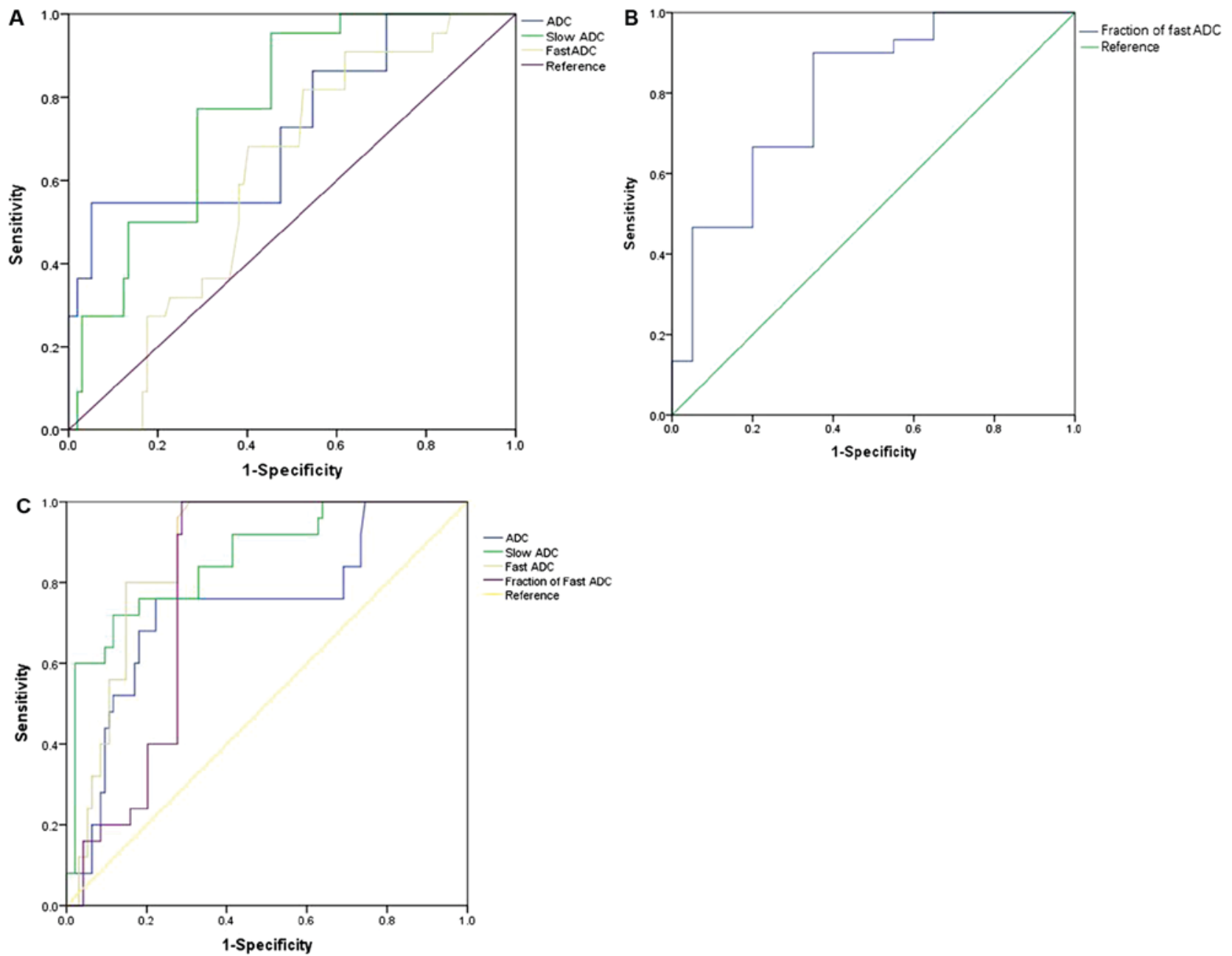

Figure 3. ROC curves were used to compare the sensitivities and specificities of different parameters in breast cancer. ROC discriminated the tumor tissue (A) between Luminal A and non-Luminal A cancer (AUC, 0.731 for ADC; 0.774 for slow ADC; 0.605 for fast ADC); (B) between Luminal B (HER2-negative) and Luminal B (HER2-positive) cancer (AUC, 0.800 for fraction of fast ADC); (C) between TNBC and non-TNBC cancer (AUC, 0.742 for ADC; 0.858 for slow ADC; 0.869 for fast ADC; 0.784 for fraction of fast ADC). ROC, receiver operating characteristic; AUC, area under the curve; ADC, apparent diffusion coefficient; HER2, human epidermal growth factor receptor 2; TNBC, triple-negative breast cancer.

decreased fast ADC values in ER positive tumors may be associated with a decreased perfusion contribution. It has also been reported that MVD and the vascular endothelial growth factor (VEGF) status of tumors were markedly associated with tumor angiogenesis, infiltration of vessels and tissues by tumor cells, and the recruitment of existing vessels by the tumor $(44,45)$. These factors provide a suitable foundation for the infiltration and transfer of the tumor (46). It has been suggested that positive ER expression may inhibit tumor angiogenesis by lowering VEGF levels (47). The present study confirmed that ER negative tumors exhibited increased tumor angiogenesis compared with ER positive tumors using MVD. These results indicated that ER positive tumors also have a decreased fast ADC value compared with ER negative tumors, and a negative correlation was identified between fast ADC and ER expression. It was also identified that the fast ADC value was correlated negatively with PR expression (Table IV). PR, which is produced by ER acting on the chromosome, was regulated by ER (48). PR expression demonstrated a negative correlation with the fast ADC value (Table V). An ER positive tumor could be treated by endocrine, which has higher survival rates and an improved treatment responses than an
ER negative tumor. The present study suggests that slow ADC and fast ADC values have the potential to provide a measure of ER expression through non-invasive MRI examination.

HER2, a prognostic factor for breast cancer, is an important index of breast cancer growth and transfer via inhibiting apoptosis, promoting proliferation, increasing the invasiveness of the tumor, and promoting tumor angiogenesis and lymphangiogenesis. The present study demonstrated that HER2 positive tumors exhibited an increased fraction of fast ADC value compared with HER2 negative tumors which suggested that HER2 positive tumors experienced more angiogenesis than HER2 negative tumors. Markedly, the fraction of fast ADC value of HER2 positive tumor edge tissue was decreased compared with HER 2 negative tissue. This may be associated with decreased perfusion in the center of TNBC on account of necrosis. The fraction of fast ADC value may be a potential marker of HER2 expression, measured using IVIM.

A previous study demonstrated that the slow ADC value was negatively correlated with $\mathrm{Ki}-67$ expression, which is consistent with the present results (49), suggesting that the slow $\mathrm{ADC}$ and $\mathrm{Ki}-67$ values may be used as an improved measure to assess the cell density and proliferation status. These results 

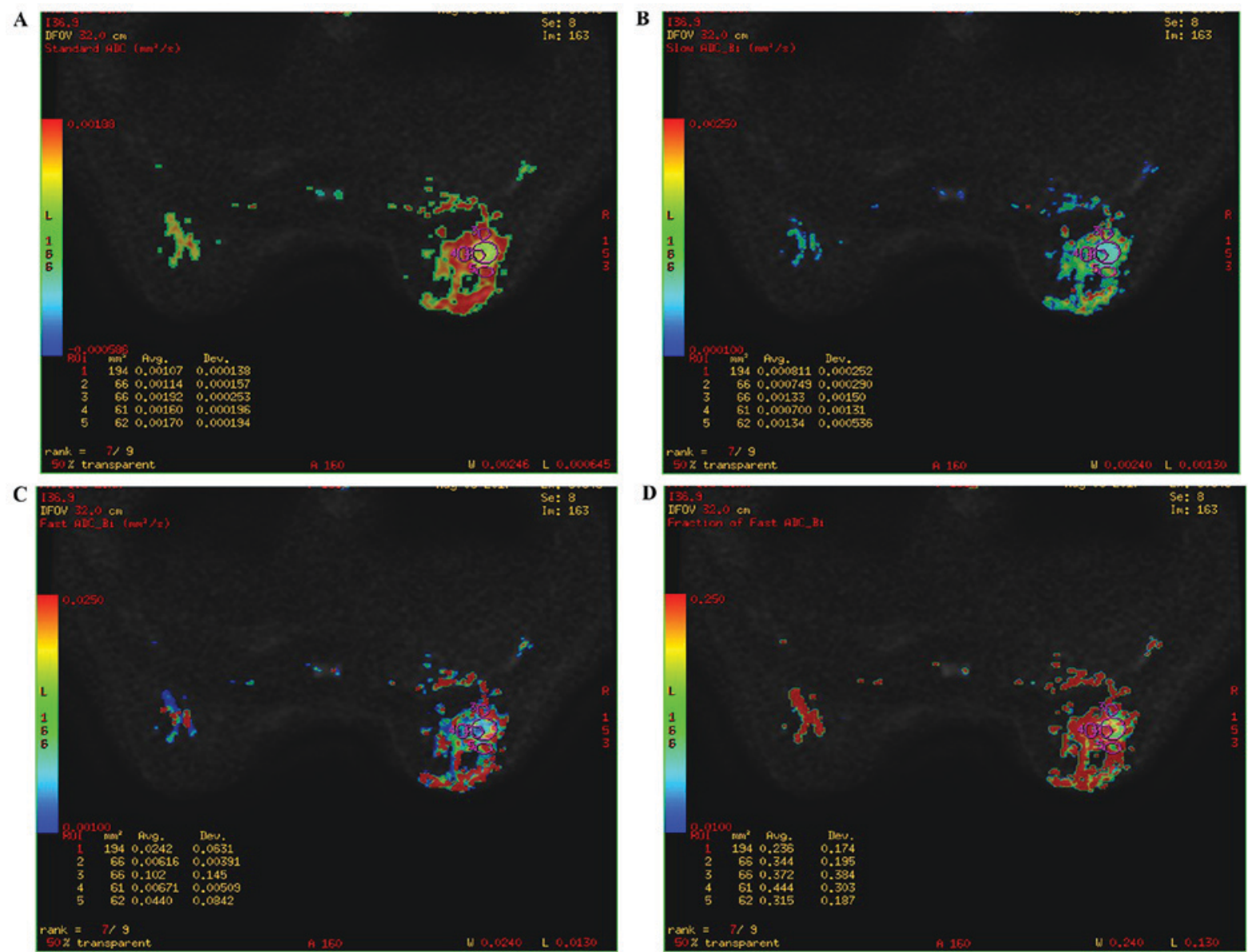

Figure 4. Magnetic resonance images of a 49-year-old female with Luminal B (HER2-positive) type invasive ductal carcinoma in the right breast. The malignant mass is presented as (A) an ADC map, (B) a slow ADC map, (C) a fast ADC map and (D) a fraction of fast ADC map. ADC, apparent diffusion coefficient; HER2, human epidermal growth factor receptor 2.

indicated that an increased cell proliferation indicated by high Ki-67 expression levels may lead to an increased cell density indicated by a decreased ADC value (25). The present results demonstrated that the fraction of fast ADC value was positively correlated with Ki-67 expression, indicating that tumor proliferation was associated with increased angiogenesis. The slow ADC and fraction of fast ADC values may be useful for assessing Ki-67. The present study also identified that tumors tissues with axillary metastasis had increased fraction of fast ADC and decreased slow ADC values compared with those without axillary metastasis.

The present study demonstrated that IVIM parameters were significantly different between different tumor subtypes. Luminal A cancer exhibited increased slow ADC and decreased fast ADC compared with other subtypes. It has previously been established that Luminal B cancers have a poorer prognosis and a distinctive response to systemic therapy, compared with Luminal A cancers (50). In the case of ER positive or PR positive tumors, the slow ADC and fast ADC values may be of use to distinguish Luminal B from Luminal A cancer. Luminal B (HER2-negative) tumor and peritumor tissues exhibited decreased fraction of fast ADC values compared with other subtypes. Gene amplification by fluorescence in situ hybridization was used to determine the HER2 status in tumors with a $2+$ score, which is a lengthy procedure. A measurement of the fraction of fast ADC may be useful to distinguish Luminal B (HER2-positive) from Luminal B (HER2-negative) cases. TNBC is associated with poor prognosis, unresponsiveness to usual endocrine therapy, and a shorter survival period (51). TNBC samples exhibited increased fast ADC and fraction of fast ADC values compared with other subtypes, which suggests that this type cancer undergoes increased tumor angiogenesis. It has been reported that TNBC also exhibited increased MVD compared with other subtypes of cancer (52). The tumor edge tissues from TNBC samples exhibited increased fraction of fast $\mathrm{ADC}$ values compared with other tissue types, including TNBC tumor tissue which may be associated with increased blood supply to the tumor and the internal necrosis of the tumor. A previous study demonstrated that circular strengthening was characteristic of TNBC, which was due to internal necrosis (51). Notably, the peritumor TNBC tissue exhibited increased fast ADC values when compared with other subtypes of breast cancer. This result indicated that TNBC cancer is a highly invasive cancer, and these changes in peritumor area of tumors may provide some assistance for the clinical evaluation of the invasive extent of tumors. However, a greater range of peritumor tissues are needed to investigate the change of parameters derived from IVIM. The present study demonstrated that the fraction of fast ADC value of the peritumor area was increased compared with that of the tumor tissue, which may be associated with the 
high $b$ value $(b>1,000)$. With the maximum $b$ value selected from the sequence of $b$-values used, the fraction of fast ADC value increased compared with lower b-values. Additionally, this may be associated with proportion of perfusion, which is greater than the diffusivity, the software, or the curve-fitting method selected. In summary, the reasons for this association remain unresolved and require further study.

The present study has a number of limitations. A selection bias of ROI may be present in the present study, since the ROI selection did not cover the entire volume of tumor, tumor edge and peritumor areas. The ROI was drawn on the slice with the largest tumor area and a small ROI was drawn on the edge of slices with high fraction of fast ADC at the largest area of tumor. The ROI of peritumor area was measured three times at the largest area of tumor and the mean value was calculated. The selection of these ROIs was to reflect the large range of tumor characteristics. Secondly, ROC analysis was not performed between all the different subtypes of breast cancer. Furthermore, an increased sample size would be necessary to perform a proper comparison and provide thresholds for distinct subtypes of breast cancer.

The objective of the present study was to compare the regional distribution between different subtypes of breast cancer using IVIM parameters. The IVIM method is important to predict the efficacy of chemotherapy in patients with breast cancer. The next step will be to evaluate the chemotherapy efficacy of different subtypes of breast cancer by IVIM.

IVIM is a valuable technique that may be useful to differentiate breast cancer subtypes, assess the invasive extent of the tumor and differentiate breast cancer from benign breast lesions. Understanding breast cancer characterization through IVIM parameters provides a new approach for appraising breast cancer accurately, which may contribute to selection of an appropriate therapeutic approach.

\section{Acknowledgments}

The authors would like to thank Dr Xl Liu and Dr Yw Cong (Pathology Center of the Second Affiliated Hospital of Harbin Medical University) for pathological support.

\section{Funding}

The present study was funded through three National Natural Science Foundations of China (grant nos. 81271647, 81630048 and 81701705).

\section{Availability of data and materials}

All data generated or analyzed during this study are included in this published article.

\section{Authors' contributions}

MZ and JT conceived and designed the study. MZ and LZ were responsible for analyzed the data. $\mathrm{KF}, \mathrm{LZ}$ and $\mathrm{ZL}$ revised the manuscript critically for important intellectual content. KF and ZL collected clinical and pathological data. WG and XB conducted the experiments and coordinated quality control of data; statistical analyses were performed by QG and QW.

\section{Ethics approval and consent to participate}

The present retrospective study was approved by the Institutional Research Board of Harbin Medical University and the requirement for informed consent was waived.

\section{Patient consent for publication}

Not applicable.

\section{Competing interests}

The authors declare that they have no competing interests.

\section{References}

1. Voduc KD, Cheang MC, Tyldesley S, Gelmon K, Nielsen TO and Kennecke $\mathrm{H}$ : Breast cancer subtypes and the risk of local and regional relapse. J Clin Oncol 28: 1684-1691, 2010.

2. Ades F,Zardavas D, Bozovic-Spasojevic I, Pugliano L, Fumagalli D, de Azambuja E, Viale G, Sotiriou C and Piccart M: Luminal B breast cancer: Molecular characterization, clinical management, and future perspectives. J Clin Oncol 32: 2794-2803, 2014.

3. Cheang MC, Chia SK, Voduc D, Gao D, Leung S, Snider J, Watson M, Davies S, Bernard PS, Parker JS, et al: Ki67 index, HER2 status, and prognosis of patients with luminal B breast cancer. J Natl Cancer Inst 101: 736-750, 2009.

4. Goldhirsch A, Wood WC, Coates AS, Gelber RD, Thürlimann B, Senn HJ and Panel members: Strategies for subtypes-dealing with the diversity of breast cancer: Highlights of the St. Gallen international expert consensus on the primary therapy of early breast cancer 2011. Ann Oncol 22: 1736-1747, 2011.

5. Goldhirsch A, Winer EP, Coates AS, Gelber RD, Piccart-Gebhart M, Thürlimann B, Senn HJ and Panel members: Personalizing the treatment of women with early breast cancer: Highlights of the St. Gallen international expert consensus on the primary therapy of early breast cancer 2013. Ann Oncol 24: 2206-2223, 2013

6. Boisserie-Lacroix M, Hurtevent-Labrot G, Ferron S, Lippa N, Bonnefoi $\mathrm{H}$ and Mac Grogan G: Correlation between imaging and molecular classification of breast cancers. Diagn Interv Imaging 94: 1069-1080, 2013.

7. Mazurowski MA, Zhang J, Grimm LJ, Yoon SC and Silber JI: Radiogenomic analysis of breast cancer: Luminal B molecular subtype is associated with enhancement dynamics at MR imaging. Radiology 273: 365-372, 2014

8. Aberle DR, Chiles C, Gatsonis C, Hillman BJ, Johnson CD, McClennan BL, Mitchell DG, Pisano ED, Schnall MD, Sorensen AG and American College of Radiology Imaging Network: Imaging and cancer: Research strategy of the american college of radiology imaging network. Radiology 235: 741-751, 2005.

9. Zhang L, Li J, Xiao Y, Cui H, Du G, Wang Y, Li Z, Wu T, Li X and Tian J: Identifying ultrasound and clinical features of breast cancer molecular subtypes by ensemble decision. Sci Rep 5: $11085,2015$.

10. Brandao AC, Lehman CD and Partridge SC: Breast magnetic resonance imaging: Diffusion-weighted imaging. Magn Reson Imaging Clin N Am 21: 321-336, 2013.

11. Padhani AR, Liu G, Koh DM, Chenevert TL, Thoeny HC, Takahara T, Dzik-Jurasz A, Ross BD, Van Cauteren M, Collins D, et al: Diffusion-weighted magnetic resonance imaging as a cancer biomarker: Consensus and recommendations. Neoplasia 11: 102-125, 2009.

12. Basser PJ: Inferring microstructural features and the physiological state of tissues from diffusion-weighted images. NMR Biomed 8: 333-344, 1995.

13. Woodhams R, Ramadan S, Stanwell P, Sakamoto S, Hata H, Ozaki M, Kan S and Inoue Y: Diffusion-weighted imaging of the breast: Principles and clinical applications. Radiographics 31: 1059-1084, 2011.

14. Atuegwu NC, Arlinghaus LR, Li X, Welch EB, Chakravarthy BA, Gore JC and Yankeelov TE: Integration of diffusion-weighted MRI data and a simple mathematical model to predict breast tumor cellularity during neoadjuvant chemotherapy. Magn Reson Med 66: 1689-1696, 2011 
15. Yoshikawa MI, Ohsumi S, Sugata S, Kataoka M, Takashima S, Mochizuki T, Ikura $\mathrm{H}$ and Imai Y: Relation between cancer cellularity and apparent diffusion coefficient values using diffusion-weighted magnetic resonance imaging in breast cancer. Radiat Med 26: 222-226, 2008.

16. Squillaci E, Manenti G, Di Roma M, Miano R, Palmieri G and Simonetti G: Correlation of diffusion-weighted MR imaging with cellularity of renal tumours. Anticancer Res 24: 4175-4179, 2004.

17. Partridge SC, DeMartini WB, Kurland BF, Eby PR, White SW and Lehman CD: Quantitative diffusion-weighted imaging as an adjunct to conventional breast MRI for improved positive predictive value. AJR Am J Roentgenol 193: 1716-1722, 2009.

18. Sinha S, Lucas-Quesada FA, Sinha U, DeBruhl N and Bassett LW: In vivo diffusion-weighted MRI of the breast: Potential for lesion characterization. J Magn Reson Imaging 15: 693-704, 2002.

19. Fornasa F, Pinali L, Gasparini A, Toniolli E and Montemezzi S: Diffusion-weighted magnetic resonance imaging in focal breast lesions: Analysis of 78 cases with pathological correlation. Radiol Med 116: 264-275, 2011.

20. Malayeri AA, El Khouli RH, Zaheer A, Jacobs MA, Corona-Villalobos CP, Kamel IR and Macura KJ: Principles and applications of diffusion weighted imaging in cancer detection, staging, and treatment follow-up. Radiographics 31: 1773-1791, 2011.

21. Le Bihan D, Breton E, Lallemand D, Grenier P, Cabanis E and Laval-Jeantet M: MR imaging of intravoxel incoherent motions: Application to diffusion and perfusion in neurologic disorders. Radiology 161: 401-407, 1986

22. Koh DM, Collins DJ and Orton MR: Intravoxel incoherent motion in body diffusion weighted MRI: Reality and challenges. AJR Am J Roentgenol 196: 1351-1361, 2011.

23. Le Bihan D, Breton E, Lallemand D, Aubin ML, Vignaud J and Laval-Jeantet M: Separation of diffusion and perfusion in intravoxel incoherent motion MR imaging. Radiology 168: 497-505, 1988.

24. Suo S, Lin N, Wang H, Zhang L, Wang R, Zhang S, Hua J and $\mathrm{Xu} \mathrm{J}$ : Intravoxel incoherent motion diffusion-weighted MR imaging of breast cancer at 3.0 tesla: Comparison of different curve-fitting methods. J Magn Reson Imaging 42: 362-370, 2015

25. Kim Y, Ko K, Kim D, Min C, Kim SG, Joo J and Park B: Intravoxel incoherent motion diffusion-weighted MR imaging of breast cancer: Association with histopathological features and subtypes. Br J Radiol 89: 20160140, 2016

26. Sigmund EE, Cho GY, Kim S, Finn M, Moccaldi M, Jensen JH, Sodickson DK, Goldberg JD, Formenti S and Moy L: Intravoxe incoherent motion imaging of tumor microenvironment in locally advanced breast cancer. Magn Reson Med 65: 1437-1447, 2011.

27. Meacham CE and Morrison SJ: Tumour heterogeneity and cancercell plasticity. Nature 501: 328-337, 2013.

28. Fisher R, Pusztai L and Swanton C: Cancer heterogeneity: Implications for targeted therapeutics. Br J Cancer 108: 479-485, 2013.

29. Polyak K: Heterogeneity in breast cancer. J Clin Invest 121: 3786-3788, 2011

30. Iima M, Yano K, Kataoka M, Umehana M, Murata K, Kanao S, Togashi K and Le Bihan D: Quantitative non-gaussian diffusion and intravoxel incoherent motion magnetic resonance imaging: Differentiation of malignant and benign breast lesions. Invest Radiol 50: 205-211,2015.

31. Liu C, Liang C, Liu Z, Zhang S and Huang B: Intravoxel incoherent motion (IVIM) in evaluation of breast lesions: Comparison with conventional DWI. Eur J Radiol 82: e782-e789, 2013.

32. Cho GY, Moy L, Kim SG, Baete SH, Moccaldi M, Babb JS, Sodickson DK and Sigmund EE: Evaluation of breast cancer using intravoxel incoherent motion (IVIM) histogram analysis: Comparison with malignant status, histological subtype, and molecular prognostic factors. Eur Radiol 26: 2547-2558, 2016.

33. Alili C, Pages E, Curros Doyon F, Perrochia H, Millet I and Taourel P: Correlation between MR imaging-prognosis factors and molecular classification of breast cancers. Diagn Interv Imag 95: 235-242, 2014.

34. Uematsu T, Kasami M and Yuen S: Triple-negative breast cancer: Correlation between MR imaging and pathologic findings. Radiology 250: 638-647, 2009.

35. Cho GY, Gennaro L, Sutton EJ, Zabor EC, Zhang Z, Giri D, Moy L, Sodickson DK, Morris EA, Sigmund EE and Thakur SB: Intravoxel incoherent motion(IVIM) histogram biomarkers for prediction of neoadjuvant treatment response in breast cancer patients. Eur J Radiol Open 4: 101-107, 2017.
36. Wolff AC, Hammond ME, Hicks DG, Dowsett $M$, McShane LM, Allison KH, Allred DC, Bartlett JM, Bilous M, Fitzgibbons $\mathrm{P}$, et al: Recommendations for human epidermal growth factor receptor 2 testing in breast cancer: American society of clinical oncology/college of American pathologists clinical practice guideline update. Arch Pathol Lab Med 138 241-256, 2014.

37. Weidner N: Intratumor microvessel density as a prognostic factor in cancer. Am J Pathhol 147: 9-19, 1995.

38. Liu C, Wang K, Chan Q, Liu Z, Zhang J, He H, Zhang S and Liang C: Intravoxel incoherent motion MR imaging for breast lesions: Comparison and correlation with pharmacokinetic evaluation from dynamic contrast-enhanced MR imaging. Eur Radiol 26: 3888-3898, 2016

39. Bokacheva L, Kaplan JB, Giri DD, Patil S, Gnanasigamani M, Nyman CG, Deasy JO, Morris EA and Thakur SB: Intravoxel incoherent motion diffusion-weighted MRI at 3.0 T differentiates malignant breast lesions from benign lesions and breast parenchyma. J Magn Reson Imaging 40: 813-823, 2014.

40. Sigmund EE, Cho GY, Kim S, Finn M, Moccaldi M, Jensen JH Sodickson DK, Goldberg JD, Formenti S and Moy L: Intravoxel incoherent motion imaging of tumor microenvironment in locally advanced breast cancer. Magn Reson Med 65: 1437-1447, 2011.

41. Jeh SK, Kim SH, Kim HS, Kang BJ, Jeong SH, Yim HW and Song BJ: Correlation of the apparent diffusion coefficient value and dynamic magnetic resonance imaging findings with prognostic factors in invasive ductal carcinoma. J Magn Reson Imaging 33: 102-109, 2011.

42. Kamitani T, Matsuo Y, Yabuuchi H, Fujita N, Nagao M, Jinnouchi M, Yonezawa M, Yamasaki Y, Tokunaga E, Kubo M, et al: Correlations between apparent diffusion coefficient values and prognostic factors of breast cancer. Magn Reson Med Sci 12: 193-199, 2013.

43. Kim SH, Cha ES, Kim HS, Kang BJ, Choi JJ, Jung JH, Park YG and Suh YJ: Diffusion-weighted imaging of breast cancer: Correlation of the apparent diffusion coefficient value with prognostic factors. J Magn Reson Imaging 30: 615-620, 2009.

44. Huuse EM, Moestue SA, Lindholm EM, Bathen TF, Nalwoga $\mathrm{H}$, Krüger K, Bofin A, Maelandsmo GM, Akslen LA, Engebraaten O and Gribbestad IS: In vio MRI and histopathological assessment of tumor microenvironment in luminal-like and basal-like breast cancer xenografts. J Magn Reson Imaging 35: 1098-1107, 2012.

45. Zhang SJ, Hu Y, Qian HL, Jiao SC, Liu ZF, Tao HT and Han L: Expression and significance of ER, PR, VEGF, CA15-3, CA125 and CEA in judging the prognosis of breast cancer. Asian Pac J Cancer Prev 14: 3937-3940, 2013.

46. Noh S, Kim do H, Jung WH and Koo JS: Expression levels of serine/glycine metabolishm-realted proteins in triple negative breast cancer tissues. Tumor Biol 35: 4457-4468, 2014

47. Biesaga B, Niemiec J and Ziobro M: Microvessel density and status of $\mathrm{p} 53$ protein as potential prognostic factors for adjuvant anthracycline chemotherapy in restrospective analysis of early breast cancer patients group. Pathol Oncol Res 18:949-960, 2012

48. Dai X, Chen A and Bai Z: Integrative investigation on breast cancer in ER, PR, and HER2-defined subgroups using mRNA and miRNA expression profiling. Sci Rep 4: 6566, 2014.

49. Mori N, Ota H, Mugikura S, Takasawa C, Ishida T, Watanabe G, Tada H, Watanabe M, Takase K and Takahashi S: Luminal-type breast cancer: Correlation of apparent diffusion coefficients with the Ki-67 labeling index. Radiology 274: 66-73, 2015.

50. Holowatyj AN, Ruterbusch JJ, Ratnam M, Gorski DH and Cote ML: HER2 status and disparities in luminal breast cancers. Cancer Med 5: 2109-2116, 2016.

51. Uematsu T: MR imaging of triple-negative breast cancer breast cancer. Breast Cancer 18: 161-164, 2011

52. Vranic S, Frkovic-Grazio S, Bilalovic N and Gatalica Z: Angiogenesis in triple-negativeadenoid cystic carcinomas of the breast. Virchows Arch 459: 377-382, 2011.

This work is licensed under a Creative Commons Attribution-NonCommercial-NoDerivatives 4.0 International (CC BY-NC-ND 4.0) License. 